
Aป1101 319004

NBSIR 82-2615

\title{
Mechanical Relaxation of Liner Materials in Acetic Acid
}

U.S. DEPARTMENT OF COMMERCE

National Bureau of Standards

National Measurement Laboratory

Polymer Science and Standards Division

Washington, DC 20234

January 1983

Jared for

QC Source Recovery Program

100

.056

N0.82-2615

$1983<.2$ 

Table of Contents

1. Introduction

2. Materials

A. Liquids

B. Liner Materials

3. Experimental

A. Stress Relaxation

B. Environmental Stress Cracking (ESC)

C. Recovery

4. Results and Discussion

A. Stress Relaxation

B. Environmental Stress Cracking (ESC)

C. Recovery

5. Conclusion

6. Acknowledgements 


\author{
Joseph C. Phillips \\ Polymer Science and Standards Division \\ National Bureau of Standards \\ Washington, D. C. 20234
}

\title{
ABSTRACT
}

This report describes stress relaxation of three liner materials [high density polyethylene (HDPE), chlorinated polyethylene (CPE), and polyvinyl chloride (PVC)] in air and acetic acid (HAC) environments. Additional experiments of environmental stress cracking (ESC) and recovery were also performed.

Experimental data for stress relaxation were obtained at temperatures of $30^{\circ} \mathrm{C}, 50{ }^{\circ} \mathrm{C}$ and $72{ }^{\circ} \mathrm{C}$. At the latter temperature $\left(72{ }^{\circ} \mathrm{C}\right)$ stress relaxation experiments were performed on high density polyethylene (HDPE) as a function of elongation and concentration (Acetic Acid/ $\mathrm{H}_{2} \mathrm{O}$ mixtures). Environmental stress cracking experiments at $60^{\circ} \mathrm{C}$ and $90{ }^{\circ} \mathrm{C}$ were also done for HDPE using acetic acid and Igepal as ESC agents.

The stress relaxation modulus, $E(t)$, from the stress relaxation data was compared for the three liner materials at different temperatures $\left(30^{\circ} \mathrm{C}, 50^{\circ} \mathrm{C}\right.$, and $72^{\circ} \mathrm{C}$ ) and strain levels. The logarithm of $\mathrm{E}(\mathrm{t})$ versus the logarithm of time and the ratio of the modulus in acetic acid to that in air showed a greater stability in strength for HDPE over the temperature and time ranges used. Chlorinated polyethylene exhibited the most deviations from linear $\log -\log$ behavior with PVC being intermediate between HDPE and CPE at all temperatures and strains tested. These results seem to suggest that the stress relaxation modulus measurements coupled with other data from such measurements as ESC and recovery may be quite useful in helping to assess the mechanical and transport behavior of a given liner material. 


\section{INTRODUCTION}

Polymers of varied chemical constitution and design have potential use as barriers for landfills. The essential purpose of these materials is to prevent or impede the leakage of liquid waste products from entering the underlying soil and ultimately polluting the groundwater. In order to better control such a hazard, one has to seek to better characterize both the transport properties and mechanical behavior of these polymeric materials. The initial investigation [1] addressed the former problem using low and high density polyethylene. This report presents the results of a study of the latter problem using stress relaxation to test the strain performance of three liner materials (high density polyethylene, HDPE; chlorinated polyethylene, CPE; polyvinyl chloride, PVC) in acetic acid.

In assessing the mechanical response of a polymer liner either to a strain and/or a sorbed liquid, the stress relaxation modulus provides information concerning the enhanced relaxation process due to sorption of any leachates $[2,3]$. If the sorption mechanism is Fickian and the diffusion constant does not depend on time (but concentration only), then transport behavior may be ascertained from relaxation modulus data [3]. Hence, by comparing modulus data of different liner materials under similar conditions of temperature, strain, and leachate, one may establish a basis for discriminating liners from their strength/time or service behavior.

In this report stress relaxation data has been presented in terms of the relaxation modulus. Experiments were performed at $30^{\circ} \mathrm{C}, 50^{\circ} \mathrm{C}$ and $72{ }^{\circ} \mathrm{C}$ using actual 1 iners made of high density polyethylene (HDPE), chlorinated polyethylene (CPE), and polyvinyl chloride $(P V C)$. The stress realxation modulus data were compared in air and acetic acid at all three temperatures and acetic acid/H $\mathrm{H}_{2} \mathrm{O}$ mixtures at $72{ }^{\circ} \mathrm{C}$. The environmental stress cracking (ESC) behavior of HDPE and CPE was also determined at $60{ }^{\circ} \mathrm{C}$ and $90{ }^{\circ} \mathrm{C}$ in acetic acid and Igepal. Recovery measurements were also done for HDPE and PVC at differen elongations and extension times. 
A. Liquids

Reagent glacial acetic acid (stress relaxation and ESC), Igepal [Nonyl phenoxy poly(ethyleneoxy ethanol)] (ESC), and distilled water (stress relaxation) were the liquids used. The acetic acid was used without further purification.

\section{B. Liner Materials}

The liner materials used in this work are given in Table I. The particular high density polyethylene used in this work is a copolymer of ethylene and propylene (also designated as a polyallomer). Chlorinated polyethylene is a rubbery material (with variable chlorine content). Each 1 iner material 1 isted in Table I has about $3 \%$ to $5 \%$ added carbon black (fine to coarse grade). Since these materials are classed as proprietary products, available information concerning exact composition is quite limited. Other thicknesses than those listed are also available as well as other polymeric materials.

\section{EXPERIMENTAL}

\section{A. Stress Relaxation}

Experiments were performed in an apparatus consisting principally of a glass jacketed tube, stretching frame, and sensor. The upper clamp was attached to the upper part of the stretching frame via a steel plate. A brass disc at the top of the clamp was positioned in proximity to the mutual induction coil of the sensor and the induced voltage due to a vertical displacement of the disc was monitored. The lower clamp was attachable to an aluminum rod which could be vertically moved through a teflon sleeve that prevented leakage of any liquid in the tube.

The strain $\varepsilon$ of the sample ( $\sim 7 \mathrm{~cm}$ long and $.5 \mathrm{~cm}$ wide) was determined by mechanically moving the aluminum rod and measuring the change in distance of fiducial marks on the sample (using a cathetometer), i.e., $\varepsilon=\Delta L / L_{0}\left(L_{0}\right.$ is the initial length; $L=L_{0}+\Delta L$ is the length after stretching). The stress on the sample was determined from a linear calibration of mass and $\mathrm{mV}$ output $(<m>=200 \mathrm{mV}$; force $=f=<m>g)$, i.e.,

* Certain commercial equipment, instruments, or materials are identified in this paper in order to adequately specify the experimental procedure. In no case does such identification imply recommendation or endorsement by the National Bureau of Standards, nor does it imply that the material or equipment identified is necessarily the best available for the purpose. 


$$
\text { Stress }=\sigma=(196 \mathrm{mV} / \mathrm{A}) \times 10^{6}
$$

and the stress relaxation modulus is given as

$$
E=\sigma / \varepsilon
$$

At each strain $\varepsilon$, the stress in Eq. (1) was corrected for changes in the area $A$, i.e., $A=A(\varepsilon)=W_{0} l_{0}\left(1+\Delta W / W_{0}\right)\left(1+\Delta l / l_{0}\right)$ where $W_{0}$ and $\ell_{0}$ are, respectively, the width and thickness of the sample at $\varepsilon=0$.

At a given temperature the experiment was begun by placing the mounted sample and stretching frame inside the glass tube. After temperature equilibrium was attained, the sample was stretched at zero time and the $\mathrm{mV}$ response was monitored as a function of time $t$ (in air). At some chosen time $t_{0}$, after the sample had relaxed in air, the liquid $\left(\mathrm{HAc}\right.$ or $\mathrm{HAc} / \mathrm{H}_{2} \mathrm{O}$ ) was poured into the tube (at temperature of the experiment) completely submerging the stretched sample (the values of $t_{0}$ ranged from $40 \mathrm{~min}$ to $1270 \mathrm{~min}$ ). The $\mathrm{mV}$ changes were once again followed as a function of time $t$ or $t-t_{0}$. The stress relaxation results at $30{ }^{\circ} \mathrm{C}, 50{ }^{\circ} \mathrm{C}$ and $72{ }^{\circ} \mathrm{C}$ at the various strains $\varepsilon$ are shown in Figures $1-7$ for the three liner materials.

B. Environmental Stress Cracking (ESC)

The apparatus for ESC was of a new design [4] to reduce scatter in the data and to control the geometry of the samples. The sample is folded over a cylindrical lower clamp and the 'free' ends inserted through an upper clamp. The clamps are attached to a glass tube that may be placed in a constant temperature bath. By anchoring the bottom clamp in the bath, the load is applied to the upper clamp by use of a pulley system. The glass tube allows a liquid to be used for ESC or the experiment may be performed in air. The ESC data for HDPE are presented in Table II for HAc, air and Igepal.

C. Recovery

The recovery measurements were performed in the same apparatus as described in section A above for stress relaxation. After the stress realxation experiment was completed on a given sample, the sample was removed from the 
apparatus and the strain was measured in air (at room temperature) as a function of time. The recovery results for HDPE and PVC are shown in Table III.

\section{RESULTS AND DISCUSSION}

A. Stress Relaxation

Stress relaxation, $\sigma(t)$, data for liner materials made of HDPE, CPE and PVC were obtained in air, acetic acid, and acetic acid/water mixtures. Experiments using air and $\mathrm{HAC}$ were performed at $30^{\circ} \mathrm{C}, 50{ }^{\circ} \mathrm{C}$ and $72{ }^{\circ} \mathrm{C}$ and the $\mathrm{HAC} / \mathrm{H}_{2} \mathrm{O}$ mixtures were done only at $72{ }^{\circ} \mathrm{C}$. These results are presented in Figs. 1-8. All the data have been plotted as the stress relaxation modulus, $E(t)$, i.e., $E(t)=\sigma(t) / \varepsilon$ where $\varepsilon$ is the imposed strain. Figure 8 shows the relaxation modulus of $\mathrm{HDPE}$ at $72{ }^{\circ} \mathrm{C}$ and $\varepsilon=.31$ versus the percentage $\mathrm{HAC}$ in a $\mathrm{HAC} / \mathrm{H}_{2} \mathrm{O}$ solution at $t-t_{0}$ equal $100 \mathrm{~min}$. and $1000 \mathrm{~min}$. In Fig. 9 the modulus for HDPE at $\varepsilon=.24$ is plotted versus the reciprocal temperature at $t-t_{0}$ equal $100 \mathrm{~min}$ and $1000 \mathrm{~min}$ (the air result is also shown). In Fig. 10 the relative modulus (acetic acid/air) is plotted versus $t-t_{0}$ at $50{ }^{\circ} \mathrm{C}$ and $\varepsilon=.44$ for HDPE, CPE and PVC.

When a sample is uniaxially extended to an elongation $\varepsilon$ and held constant, the stress relaxes in a manner dependent on the nature of the polymer, the strain level, the temperature, and the environment (vacuum, gas, vapor or 1 iquid). In air at $30{ }^{\circ} \mathrm{C}, 50{ }^{\circ} \mathrm{C}$ and $72{ }^{\circ} \mathrm{C}, \mathrm{HDPE}, \mathrm{PVC}$ and CPE exhibited a normal relaxation behavior [5] as shown in Figs. 1-3 over the time and strain range given, i.e.,

$$
\log E(t)=\log k+\alpha \log t
$$

where $k$ is a function of $\varepsilon$ and $\alpha$ is the slope of the $\log -10 \mathrm{~g}$ plot. It can be seen from Figs. 1-3 that the slope a depends on the nature of the 1iner material and the temperature. For HDPE the slope shows little if any variation with temperature while the slope for PVC is slightly more negative and CPE has an even greater negative slope. Although the results are not shown, at $72{ }^{\circ} \mathrm{C}$ 
for CPE in air the modulus completely relaxes to zero in two minutes. The linear behavior exhibited by Eq. (3) generally holds for materials over extended decades of time if the material does not undergo extensive structural changes or craze formations [5].

As a stretched uncrosslinked polymer undergoes the sorption of a gas, liquid or vapor, the modulus or stress will relax faster than that of the dry material $[2,3]$. The enhanced relaxation may be diffusion-controlled and accompanied by scission of interchain bonds or by a plasticizing effect. The former mechanism predominates at an experimental temperature below the glass transition $\left(T_{g}\right)$ while the latter mechanism is controlling at $T \gg T_{g}$ [2]. Even though the two mechanisms always act concurrently and cooperatively, their relative importance may also depend on the nature of the polymer and the experimental conditions.

In Figures 4-6, the relaxation modulus of the liner materials in acetic acid has been plotted versus $t-t_{0}$. In some cases one could also represent the data in a $\log -\log$ fashion, i.e.,

$$
\log E(t)=\log k+\beta \log \left(t-t_{0}\right)
$$

where $E(t)$ is the modulus due to the presence of $H A c, \log k$ is a constant, $\beta$ is the slope, and $t-t_{0}$ is the characteristic time of the sorption process. At $30^{\circ} \mathrm{C}$ (Fig. 4), HDPE show a behavior very similar to that in air, i.e., $\beta \sim \alpha$ and $K$ is a function of $\varepsilon$; at $50{ }^{\circ} \mathrm{C} \beta$ for HDPE (Fig. 5) seems to change at low $\varepsilon$. This would suggest some difference in relaxation rate below some critical strain, but the data are too sparse to make any further comment; at $72{ }^{\circ} \mathrm{C}$, $\beta$ for $H D P E$ (Fig. 6) is approximately equal to the a value for relaxation in air. The change of $E(t)$ for CPE in HAC is dramatically different than that in air as shown by the rapid drop in modulus in Figs. 4 and 5 ; at $72{ }^{\circ} \mathrm{C}$, the modulus for CPE was not measurable due to an extremely rapid drop in modulus to zero immediately after stretching the sample. The only significant changes of the modulus in HAC for PVC versus that in air occurred at $72{ }^{\circ} \mathrm{C}$ for a high strain $(\varepsilon=.89)$. 
The empirical results represented by Eqs. (3) and (4) expresses the fact that the modulus relaxation rate may be conveniently represented at a given temperature and strain-level from the linearized data, i.e.,

or

$$
d E(t) / d t=\alpha E(t) / t
$$

$$
d E\left(t-t_{0}\right) / d\left(t-t_{0}\right)=\beta E\left(t-t_{0}\right) / t-t_{0}
$$

As shown in Figs. 1-3, the slope $\alpha$ in air seems to be independent of time $t$ over the range shown for all three materials, but the relative differences in $\alpha$ also suggest a different relaxation rate ( $C P E>P V C>H D P E)$. In HAC the slope $\beta$ for HDPE is approximately equal to that of $\alpha$ at each temperature, but for CPE at $50{ }^{\circ} \mathrm{C}$ and PVC at $72{ }^{\circ} \mathrm{C}$ one observes a time dependence of $\beta$. As long as the data may be represented as a linear plot, one may assume that there exists a $\log$ normal distribution of relaxation times $[5,6]$, otherwise, any time dependence of $\alpha$ and $\beta$ means deviations from the normal distribution.

In the actual field use of liner materials, the effects of mixtures such as $\mathrm{HAc} / \mathrm{H}_{2} \mathrm{O}$ on the stress relaxation modulus must also be taken into account in evaluating these materials [7]. Figure 7 for HDPE at $72{ }^{\circ} \mathrm{C}$ shows that the modulus changes less than a factor of two for $\varepsilon=.24$ to .66 and a concentration of HAC from $0 \%$ to $100 \%$. Figures 8 shows the variation of the modulus for HDPE decreases at a given value of $t-t_{0}$ from the $100 \% \mathrm{H}_{2} \mathrm{O}$ value to that of $0 \% \mathrm{H}_{2} \mathrm{O}$ in a $\mathrm{HAc} / \mathrm{H}_{2} \mathrm{O}$ mixture. These results in Figs. 7 and 8 suggest that the dilution of $\mathrm{HAc}$ with $\mathrm{H}_{2} \mathrm{O}$ affects the modulus dramatically only at high $\mathrm{H}_{2} \mathrm{O}$ concentrations ( $80 \%-100 \%)$. This behavior roughly parallels that of $\mathrm{PVAc} / \mathrm{H}_{2} \mathrm{O}$ [2] in which the modulus has its greatest variation at high relative humidity vapor pressures of $\mathrm{H}_{2} \mathrm{O}$. In many cases, concentration effects of the modulus may be handled conveniently through the use of a concentration shift factor [2]. Such data treatment allows for the construction of a master curve that shows over a wide time-temperature range the different types of viscoelastic behavior $[2,6]$. 
The data in Fig. 9 suggest that for HDPE at $\varepsilon=.24$ the modulus is roughly linear with the reciprocal temperature for the times indicated. At very high strains in which the sample may be highly plastically drawn, such a linear or parallel relationship may not be found; at temperatures much lower or higher than the range given in Fig. 9 the behavior may also become non-linear [6]. The behavior of $E\left(t-t_{0}\right)$ for CPE versus $1 / T$ would be expected to be highly non-linear, because at $72{ }^{\circ} \mathrm{C}$ the relaxation modulus at $t-t_{0}=100$ and 1000 is zero in acetic acid. The PVC liner material behaves somewhat intermediate to HDPE and CPE. In air HDPE and PVC behave similarly to the results in Fig. 9, but CPE is expected to once again be highly non-linear due to the fact its modulus goes to zero immediately after stretching at $72{ }^{\circ} \mathrm{C}$.

The data presented in Fig. 10 was chosen to show how the stress relaxation results may be used as a screening test for discriminating various polymers for liner use under given conditions. The parameter used for comparison is the ratio of the modulus in the liquid (e.g., acetic acid) to that in air versus the time $t-t_{0}$. As seen from Fig. 10 at $50^{\circ} \mathrm{C}$ and $\varepsilon=.44$, the HDPE material maintains $i$ ts strength over a much longer time interval than the other two polymers. The CPE material has a very short-term, strength-time behavior with PVC being intermediate. The closer the ratio is to unity over an extended time period, the more useful the material is in maintaining its air behavior versus that in the liquid environment. It may be noted that the PVC data (if curve is drawn through all points) seems to indicate the possible occurrence of crystallization. Such behavior is known to occur for certain polymers exposed to a given vapor or liquid $[8,9]$. Hence, in addition to modulus changes due to the plasticization process, secondary effects such as crystallization are also important in determining the overall long-term behavior [8]. 


\section{B. Environmental Stress Cracking (ESC)}

The ESC data for HDPE are presented in Table II for air, HAC, and Igepal at $60{ }^{\circ} \mathrm{C}$ and $90{ }^{\circ} \mathrm{C}$. At a load of $5.01 \times 10^{6} \mathrm{~N} / \mathrm{m}^{2}$ no stress cracking was observed in air, $H A C$, or Igepal at $60^{\circ} \mathrm{C}$. A load of $210 \times 10^{6} \mathrm{~N} / \mathrm{m}^{2}$ produced a drawing in Igepal but no breaking. By increasing the temperature to $90{ }^{\circ} \mathrm{C}$ at the initial load, the sample elongated and broke within 1 day [HAc was not used at this temperature due to its corrosive action on the apparatus]. The polymer CPE and PVC at a load of $5.01 \times 10^{6} \mathrm{~N} / \mathrm{m}^{2}$ only "drew" at $60^{\circ} \mathrm{C}$ (no breaking occurred) in air, HAC, and Igepal.

The results presented in Table II suggest that the HDPE liner material is somewhat inert to the ESC action of HAC (including Igepal) over the strain and temperature range of the stress relaxation experiments. This result must be taken very cautiously, because it is known that the change in stiffness of HDPE due to Igepal depends on other factors such as the density, processing histories (cooling rates), and added plasticizer content [9].

\section{Recovery}

Some recovery data for HDPE and PVC are presented in Table III. The CPE material behaves similarly to PVC. Each sample was stretched to an initial strain $\varepsilon$ and at a time $t_{0}$ stress relaxation was performed in HAc. After a total time $t_{h}\left(=t_{0}+\Delta t ; \Delta t=\right.$ elapsed time during stress relaxation in $\left.H A C\right)$, the sample was allowed to recover in air for a given period of time by suddenly reducing the stress to zero.

The degree to which a sample recovers depend on the extension time $t_{h}$, the sorbed liquid, and the strain $\varepsilon[10,11]$. The effect of each factor is the enhancement of the plastic strain, $\varepsilon_{p \ell}$, with a concomitant decrease in the elastic strain, $\varepsilon_{e}$, i.e.,

$$
\varepsilon=\varepsilon_{e}+\varepsilon_{p l}
$$


where the total strain $\varepsilon$ is constant. When the end constraints of the sample are removed, the sample immediately recovers to the instantaneous elastic strain, $\varepsilon_{e}(0)$, and the instantaneous plastic strain, $\varepsilon_{p l}(0)$ slowly decreases to $\varepsilon_{p \ell}(\infty)$, i.e., structural changes due to stretching or the presence of a sorbed liquid increases with $t_{h}$ and the sample never recovers completely to the original state, but eventually reaches a permanent set condition, $\varepsilon_{p l}(\infty)$. These structural changes with time are manifested in measurements of diffusivity and solubility [10]. Over a given time interval, the former transport property may differ in a sorption and desorption process while the latter property may show little or no differences [10]. Hence, the information obtained from the recovery experiment is quite useful in supplying information about the effects of strain and sorbed liquid on a given sample.

\section{CONCLUSION}

This investigation has presented stress relaxation data on HDPE, PVC, and CPE as a function of temperature and strain in acetic acid and mixtures of $\mathrm{HAC} / \mathrm{H}_{2} \mathrm{O}$. The temperature and strain behavior of the liner materials show distinct differences in changes of the stress relaxation modulus. The environmental stress cracking measurements of HDPE and CPE showed that at the imposed stress loads used, acetic acid and Igepal were not ESC agents at $60^{\circ} \mathrm{C}$, but Igepal did stresscrack HDPE at $90{ }^{\circ} \mathrm{C}$. Recovery data for HDPE and PVC presented additional information as to the strain behavior of these materials when the stress is reduced to zero.

This investigation has attempted to show how the relaxation modulus may be used as a distinguishing parameter for different liner materials under the influence of a given strain or stress. This seems to be conveniently done by using the relative stress relaxation modulus, i.e., the ratio of the modulus in liquid to that in air versus time. Further defined studies may show this parameter to be quite useful in characterizing the mechanical relaxation of potential liner materials. Although this study did not address 
the question of failure as a function of stress load or biaxial deformation, these experiments are indeed necessary for a more complete mechanical and transport appraisal of a given liner material.

\section{ACKNOWLEDGEMENTS}

Appreciation is expressed to Dr. Henry E. Haxo, Jr. of Matrecon, Inc. for supplying the liner materials and Dr. John M. Crissman of NBS for the use of the environmental stress cracking (ESC) apparatus and the measurement of some of the ESC data.

\section{REFERENCES}

1. Phillips, J. C., NBSIR Report: Transport of Acetic Acid in Polyethylene, to be published.

2. Fujita, H. and Kishimoto, A., J. Polym. Sci. 28, 547 (1958).

3. Kishimoto, A. and Fujita, H., J. Polym. Sci. 28, 569 (1958).

4. Crissman, J., (NBS), unpublished data.

5. Litt, M. H. and Torp, S., unpublished data.

6. Ferry, J. D., "Viscoelastic Properties of Polymers", 2nd ed., John Wiley and Sons, Inc., New York, 1970.

7. Bondi, A., "Physical Properties of Molecular Crystals, Liquids and Glasses", John Wiley and Sons, New York, NY, 1968.

8. Kambour, R. P., Karasz, F. E. and Daane, J. H., J. Polym. Sci. 4, Part A-2, $327(1966)$.

9. Frayer, P. D., Long, P. P. and Dreher, W. W., Polym. Eng. Sci. 17, 27 (1977).

10. Phillips, J. C., Polym. Eng. Sci., to be published.

11. Djiauw, L. K. and Gent, A. N., Polym. Preps. 14, 62 (1973). 


\section{LIST OF TABLES}

I. Density and Thickness of Liner Materials.

II. Environmental Stress Cracking of HDPE.

III. Recovery of HOPE and PVC.

\section{LIST OF FIGURES}

1. Relaxation Modulus Versus Time $(t)$, HDPE, CPE in air $\left(30^{\circ} \mathrm{C}\right)$.

2. Relaxation Modulus Versus Time $(t)$, HDPE, CPE, PVC in air $\left(50^{\circ} \mathrm{C}\right)$.

3. Relaxation Modulus Versus time $(t)$, HDPE, PVC in air $\left(72{ }^{\circ} \mathrm{C}\right)$.

4. Relaxation Modulus Versus Time $\left(t-t_{0}\right)$, HDPE, CPE in HAC $\left(30^{\circ} \mathrm{C}\right)$.

5. Relaxation Modulus Versus Time $\left(t-t_{0}\right)$, HDPE, CPE in HAC $\left(50^{\circ} \mathrm{C}\right)$.

6. Relaxation Modulus Versus Time $\left(t-t_{0}\right)$, HDPE, PVC in HAC $\left(72{ }^{\circ} \mathrm{C}\right)$.

7. Relaxation Modulus Versus Time $\left(t-t_{0}\right), \mathrm{HDPE} /\left(\mathrm{HAC} / \mathrm{H}_{2} \mathrm{O}\right)\left[72^{\circ} \mathrm{C}\right]$.

8. Relaxation Modulus Versus Volume $\% \mathrm{HAC}, \varepsilon=.31\left(72{ }^{\circ} \mathrm{C}\right)$.

9. Relaxation Modulus Versus Reciprocal Temperature $(1 / T), \varepsilon=.24$.

10. Relative Relaxation Modulus Versus Time $\left(t-t_{0}\right), \varepsilon=.44\left(50^{\circ} \mathrm{C}\right)$. 
Table I. DENSITY AND THICKNESS OF LINER MATERIALS (ACTUAL "FIELD" MATERIALS).

Material $^{\mathrm{a}}$

HDPE

CPE

PVC
Thickness, $\mathrm{cm}$

.102

.0762

.0762 density, $\mathrm{g} / \mathrm{cm}^{3}\left(25^{\circ} \mathrm{C}\right)$

.95

1.22

a Designations: $H D P E=$ high density polyethylene; $C P E=$ chlorinated polyethylene; $P V C=$ polyvinyl chloride.

Table II. ENVIRONMENTAL STRESS CRACKING (ESC) OF HDPE LINER MATERIAL $($ THICKNESS $=.102 \mathrm{~cm})$.

Material Temperature $\frac{\text { ESC Agent }}{\left({ }^{\circ} \mathrm{C}\right)} \underline{\text { Time (days) }}$ Load $\left(\mathrm{N} / \mathrm{m}^{2}\right)$ Results

$\begin{array}{lllrrr}\text { HDPE } & 60 & \text { Acetic Acid } & 24 & 5.01 \times 10^{6} & \text { no effect } \\ \text { HDPE } & 60 & \text { Air } & 24 & 5.01 \times 10^{6} & \text { no effect } \\ \text { HDPE } & 60 & \text { Igepal } & 44 & 5.01 \times 10^{6} & \text { no effect } \\ \text { HDPE } & 90 & \text { Igepal } & 1 & 5.01 \times 10^{6} & \begin{array}{l}\text { sample } \\ \text { elongates } \\ \text { \& breaks }\end{array}\end{array}$

TABLE III. RECOVERY DATA FOR LINER MATERIALS

$\frac{\text { Material }}{\text { Initial Elongation }}{ }^{a} \quad \frac{\text { Elongation }^{b} \text { at time } t}{(\%)} \quad$ Time, $t$ (days)

$\begin{array}{lrrr}\text { HDPE } & 35 & 16 & 3 \\ \text { HDPE } & 24 & 13 & 7 \\ \text { PVC } & 42 & 16 & 3 \\ \text { PVC } & 89 & 69 & 30\end{array}$

${ }^{a}$ Sample was initially stretched in air at $72{ }^{\circ} \mathrm{C}$ and stress relaxation was subsequently performed in acetic acid.

bample was removed from acetic acid and clamps; sample recovery was performed at time $t$ in air at room temperature. 


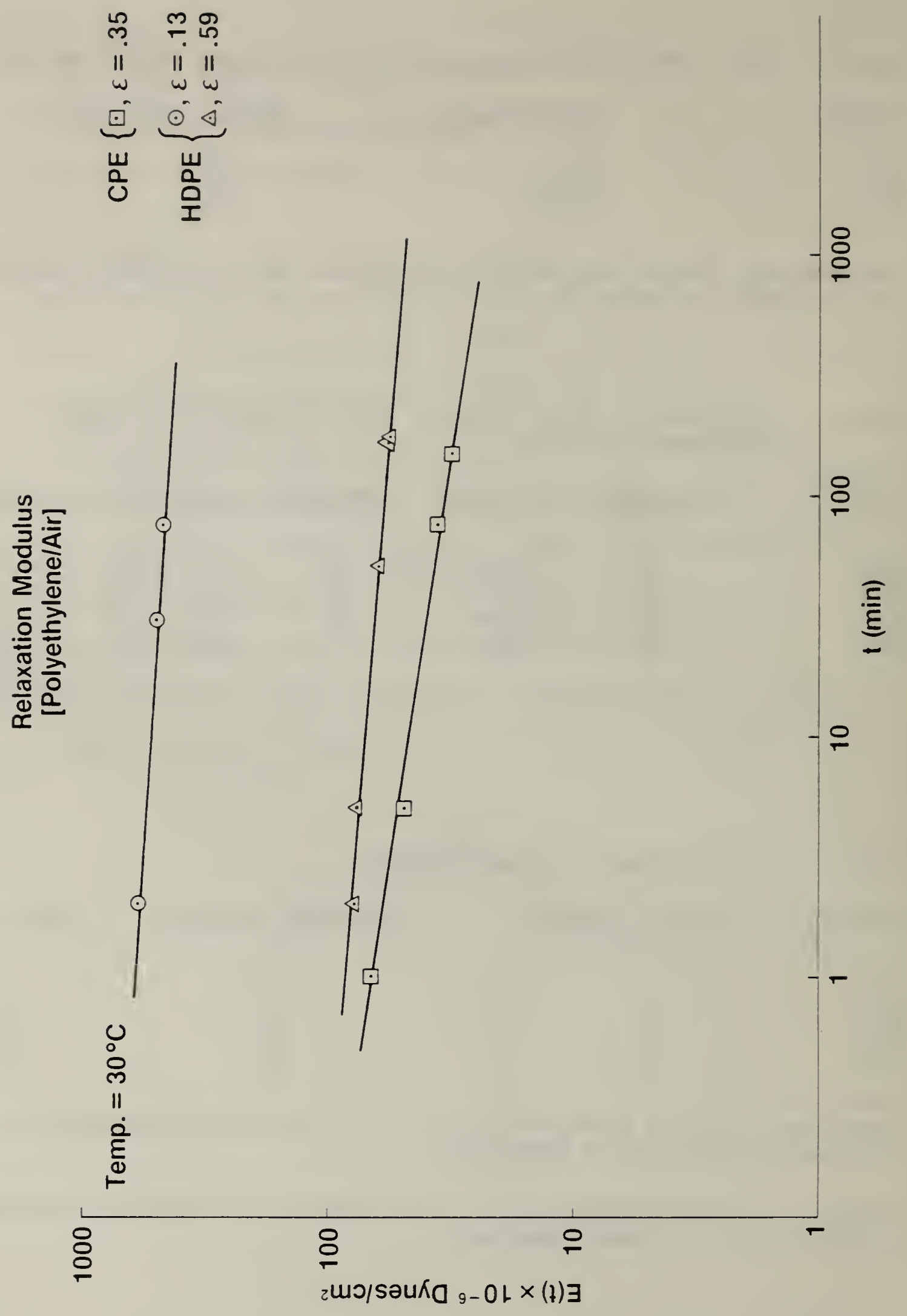




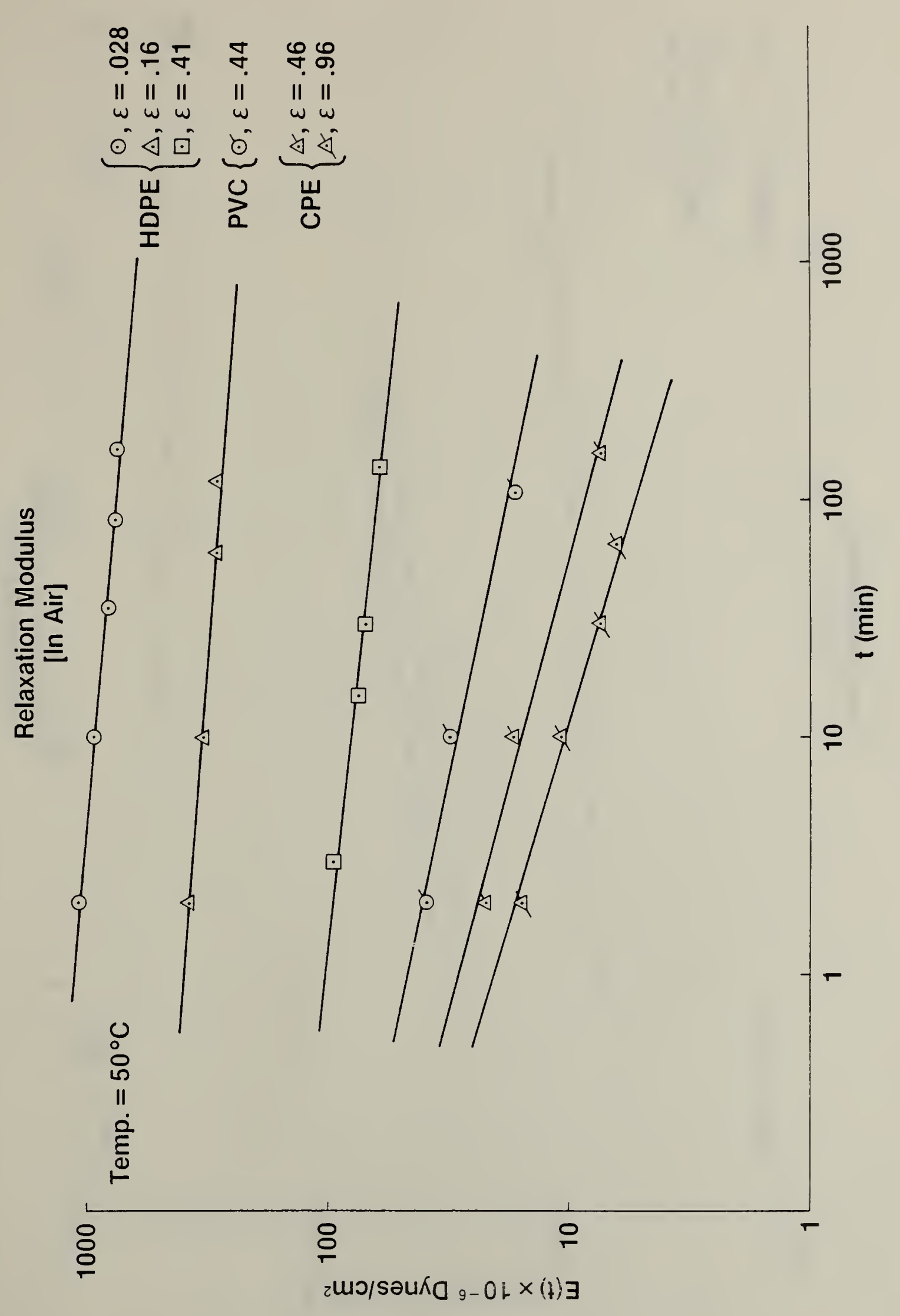




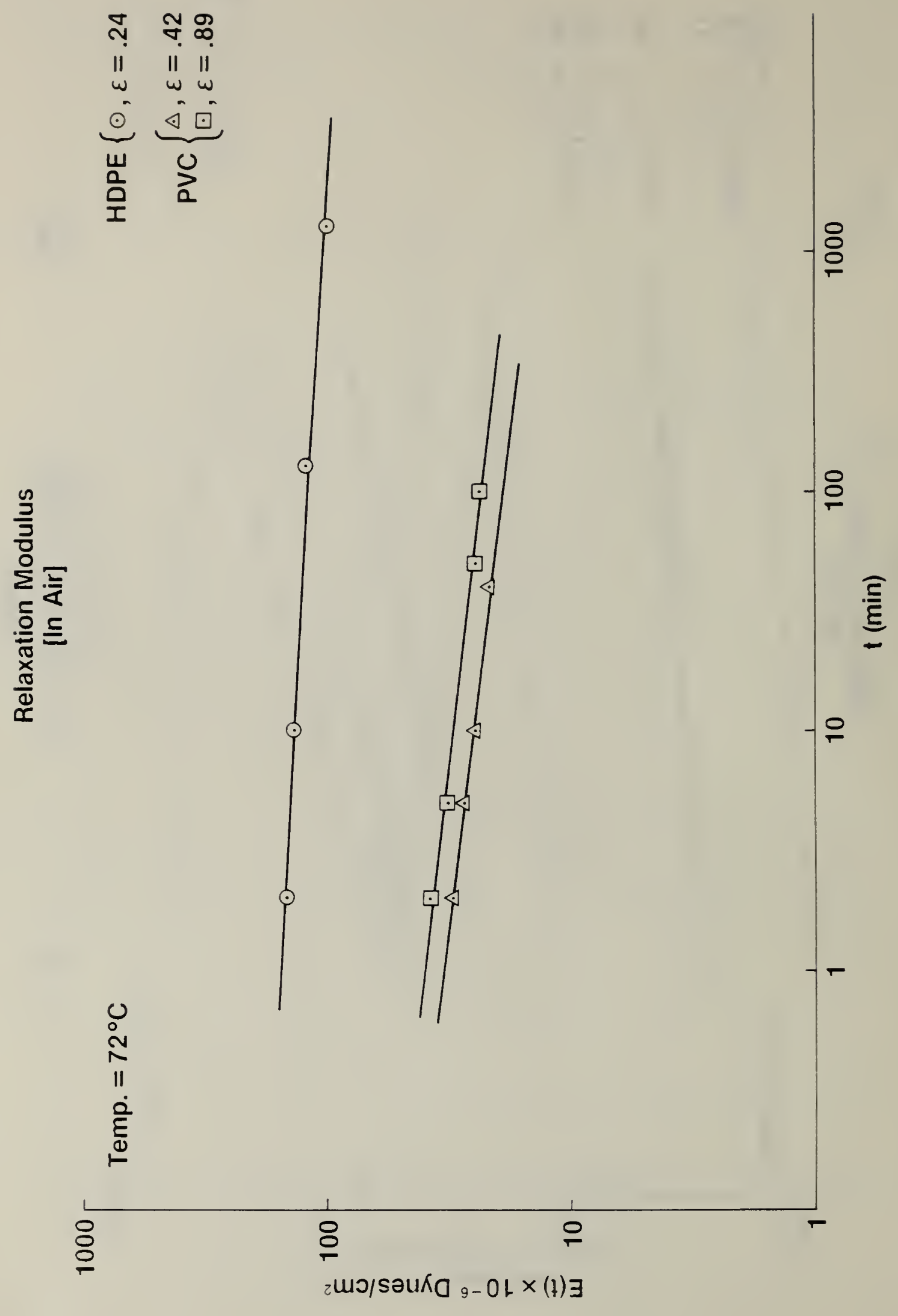




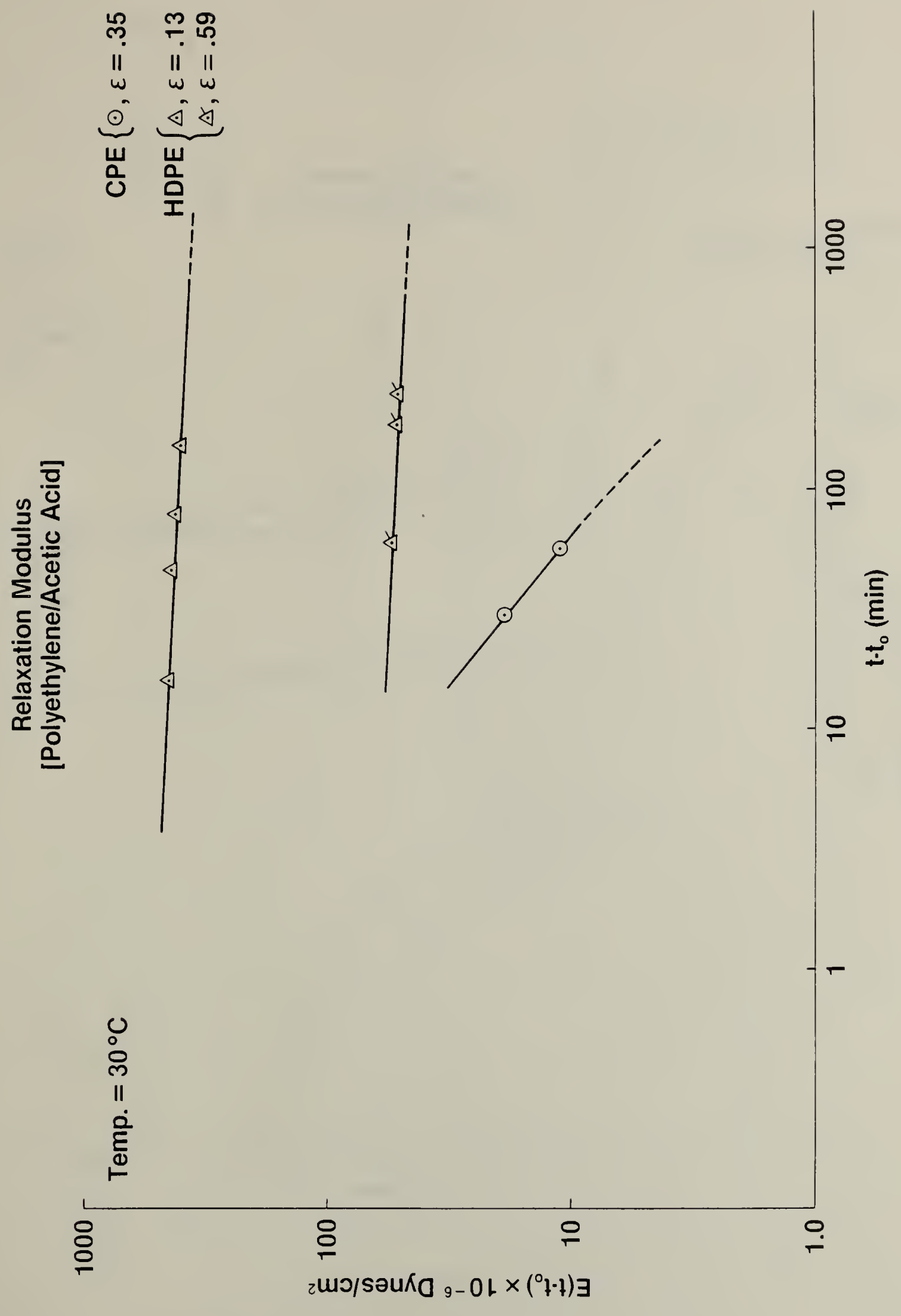


Relaxation Modulus

[Polyethylene/Acetic Acid]

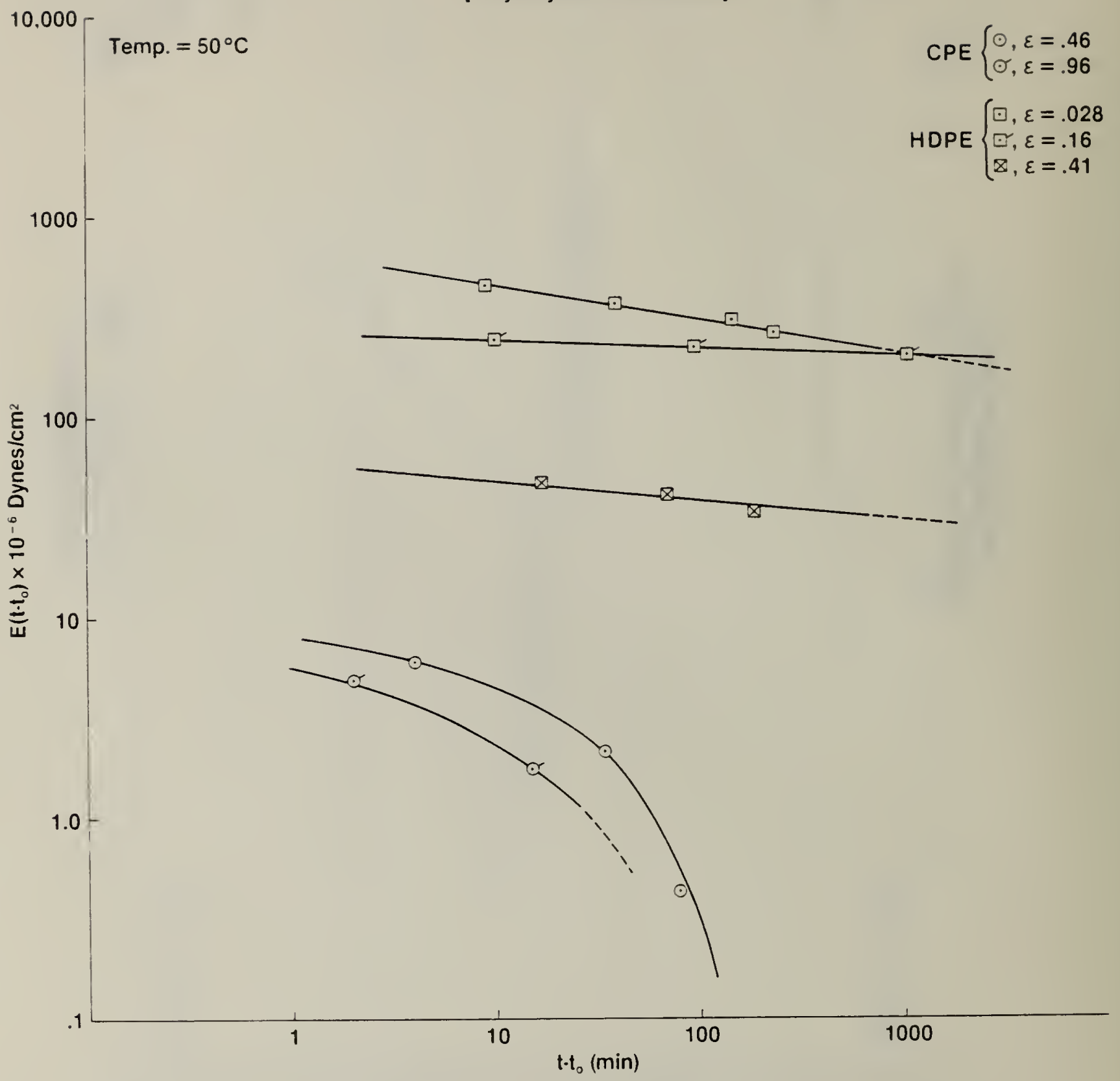

Fig.5 


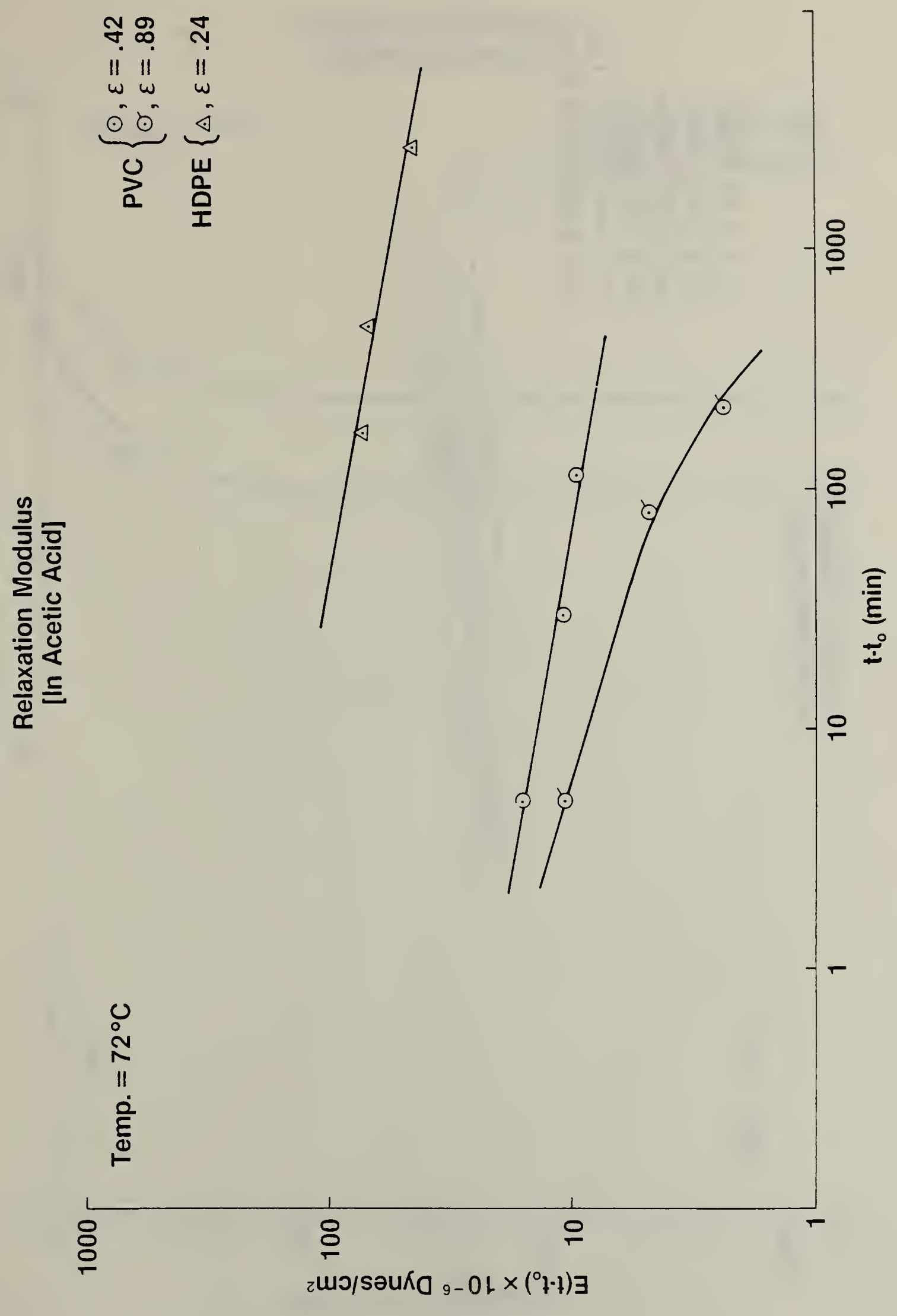




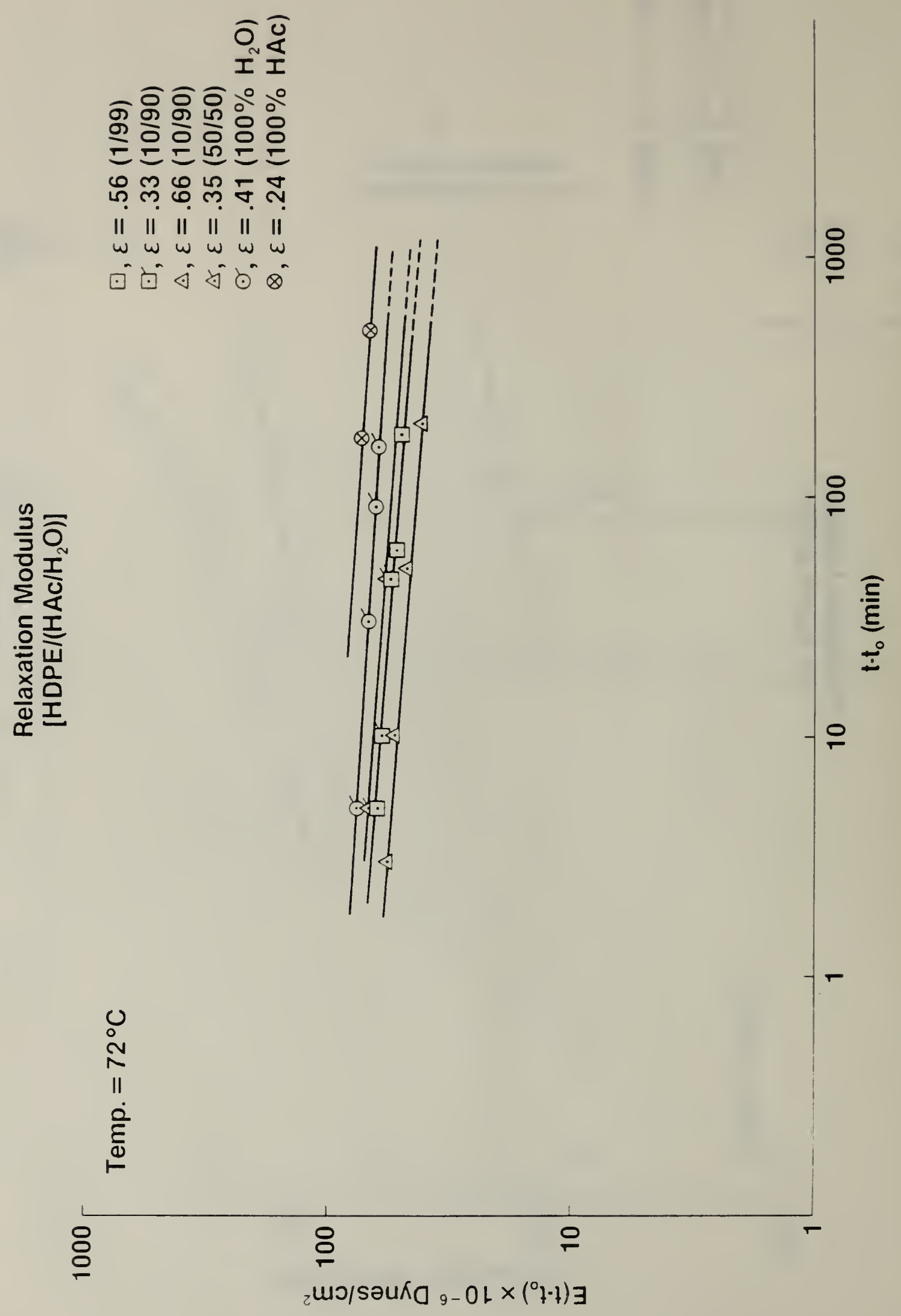


Relaxation Modulus

[HDPE/( $\left.\mathrm{HAc} / \mathrm{H}_{2} \mathrm{O}\right)$ ]

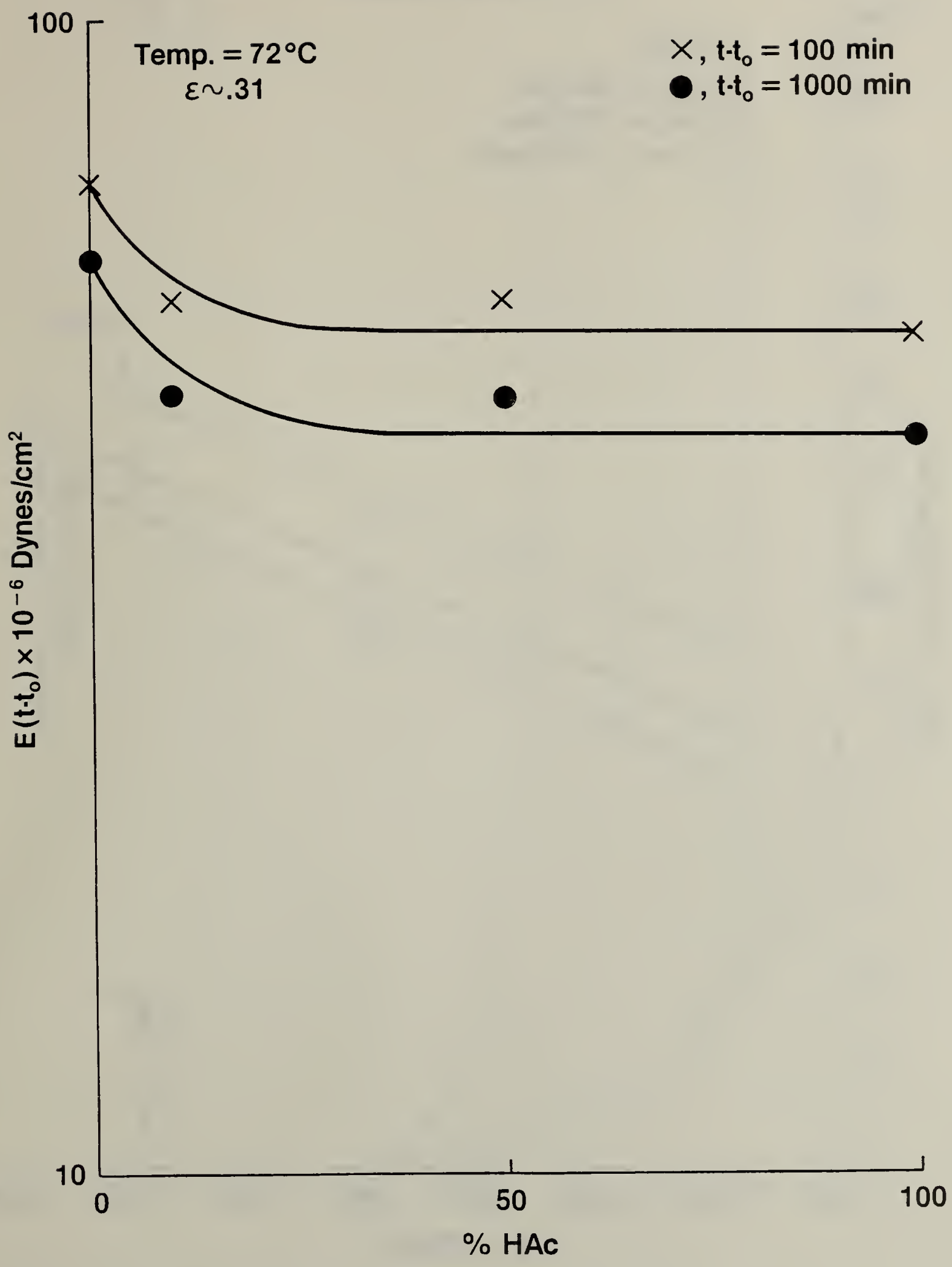




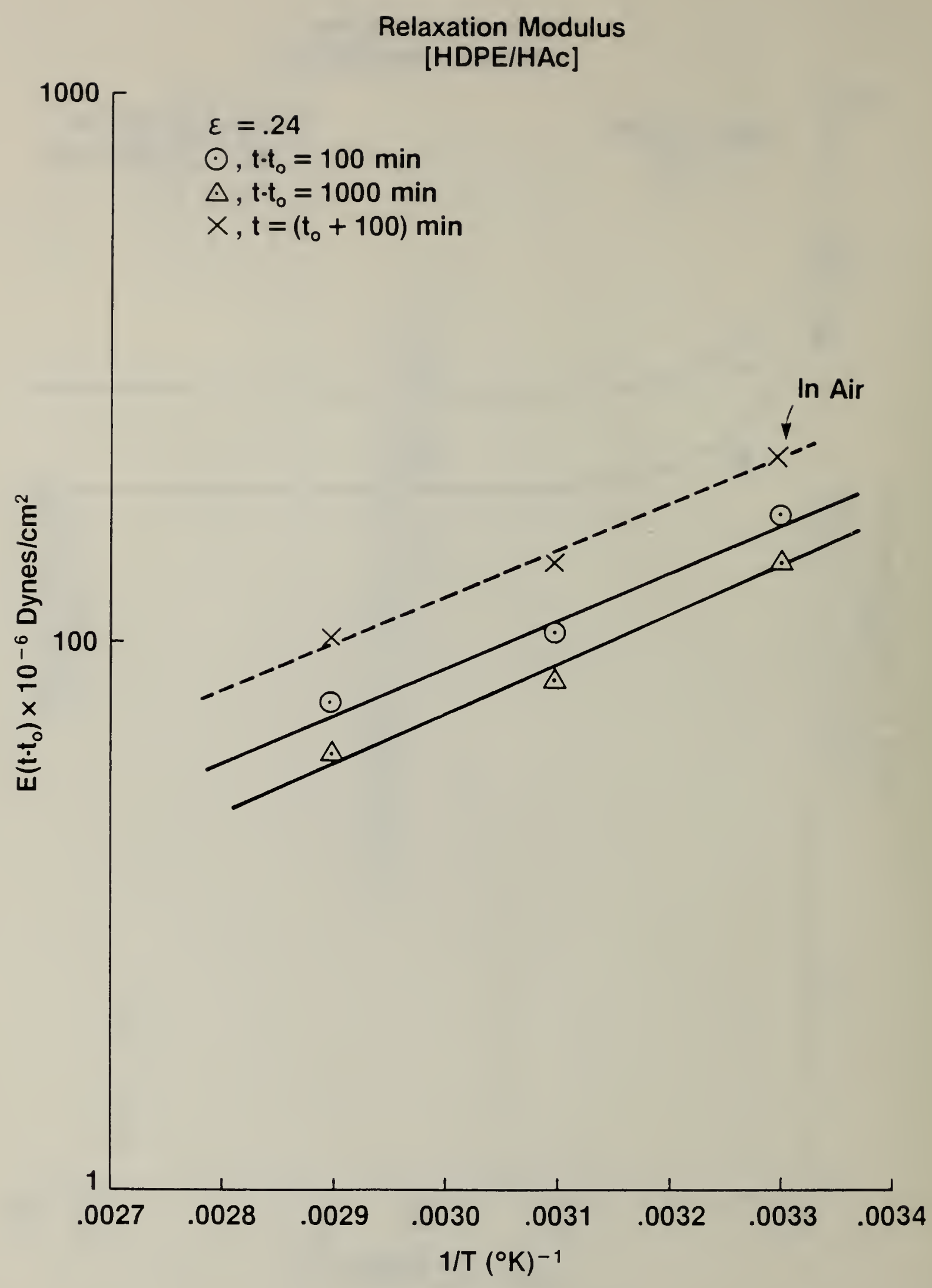

Fig. 9 


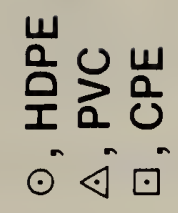

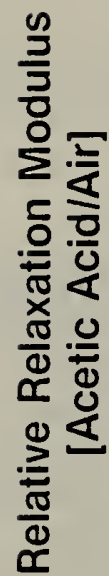

웅

II II

을 $^{\omega}$

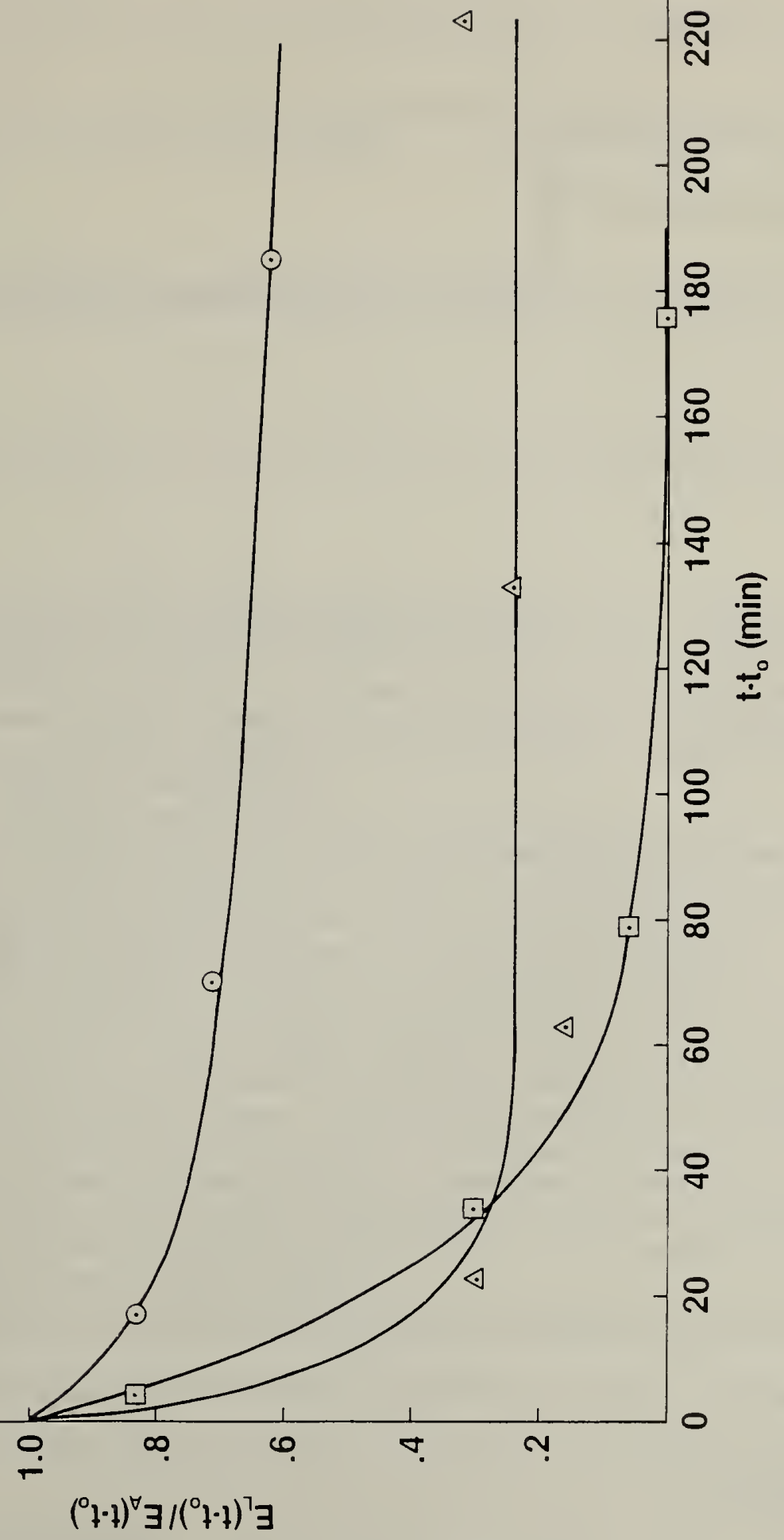



NBS-114A (REV. 2-8C)

\begin{tabular}{|c|c|c|c|}
\hline U.S. DEPT. OF COMM. & 1. PUBLICATION OR & 2. Performing Organ. Report No & 3. Publication Date \\
BIBLIOGRAPHIC DATA & NBSIR $32-2615$ & & January 1983 \\
SHEET (See instructions) & NBSIRA & & \\
\hline
\end{tabular}

4. TITLE AND SUBTITLE

MECHANICAL RELAXATION OF LINER MATERIALS IN ACETIC ACID

5. $A \cup T H O R(S)$

Joseph C. Phillips

\begin{tabular}{l|l} 
6. PERFORMING ORGANIZATION (If joint or other than NBS, see instructions) & 7. Contract Grane No.
\end{tabular}

NATIONAL BUREAU OF STANDARDS

DEPARTMENT OF COMMERCE

WASHINGTON, D.C. 20234

9. SPONSORING ORGANIZATION NAME AND COMPLETE ADDRESS (Street. City. Stote, ZIP)

8. Type of Report \& Period Covered

10. SUPPLEMENTARY NOTES

[- Document describes a computer program: SF-185, FIPS Software Summary, is attached.

11. ABSTRACT (A 200-word or less factual summary of most significant information. If document includes a significant bibliography or literature survey. mention it here)

This report describes stress relaxation of three liner materials [high density polyethylene (HDPE), chlorinated polyethylene (CPE), and polyvinyl chloride (PVC)] in air and acetic acid (HAc) environments. Additional experiments of environmental stress cracking (ESC) and recovery were also performed.

Experimental data for stress relaxation were obtained at temperatures of $30^{\circ} \mathrm{C}$, $50^{\circ} \mathrm{C}$ and $72^{\circ} \mathrm{C}$. At the latter temperature $\left(72^{\circ} \mathrm{C}\right)$ stress relaxation experiments were performed on high density polyethylene (HDPE) as a function of elongation and concentration (Acetic Acid/ $\mathrm{H}_{2} \mathrm{O}$ mixtures). Environmental stress cracking experiments at $60^{\circ} \mathrm{C}$ and $90^{\circ} \mathrm{C}$ were also done for HDPE using acetic acid and Igepal as ESC agents.

The stress relaxation modulus, $\mathrm{E}(\mathrm{t})$, from the stress relaxation data was compared for the three liner materials at different temperatures $\left(30^{\circ} \mathrm{C}, 50^{\circ} \mathrm{C}\right.$, and $\left.72^{\circ} \mathrm{C}\right)$ and strain levels. The logarithm of $E(t)$ versus the logarithm of time and the ratio of the modulus in acetic acid to that in air showed a greater stability in strength for HDPE over the temperature and time ranges used. Chlorinated polyethylene exhibited the most deviations from linear $10 \mathrm{~g}-\mathrm{log}$ behavior with PVC being intermediate between $\mathrm{HDPE}$ and $\mathrm{CPE}$ at all temperatures and strains tested. These results seem to suggest that the stress relaxation modulus measurements coupled with other data from such measurements as ESC and recovery may be quite useful in helping to assess the mechanical and transport behavior of a given liner material.

12. KEY WORDS (Six to twelve entries; alphabetical order: capitalize only proper names; and separate key words ty semicolons)

Acetic Acid, mechanical relaxation, liner materials, recovery, stress cracking.

13. AVAILABILITY

Xnlimited

For Official Distribution. Do Not Release to NTIS

Order From Superintendent of Documents, U.S. Government Printing Office, Washington, D.C. 20402.

Order From National Technical Information Service (NTIS), Springfield, VA. 2216I
14. NO. OF PRINTED PAGES

15. Price 


